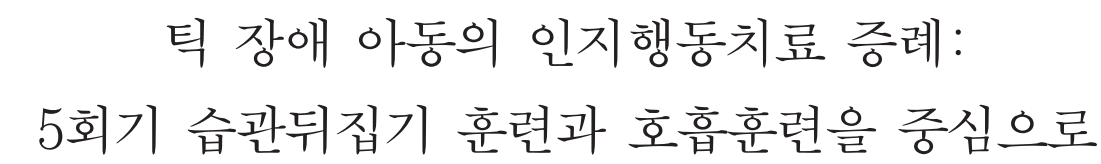

송정림 $^{1)} \cdot$ 홍종우 $^{2)} \cdot$ 도진아 $^{1)} \cdot$ 김현우 $^{2)} \cdot$ 임명호 $^{2) 3}$

단국대학교 의료원 임상심리실, ${ }^{1)}$ 단국대학교 의과대학 정신과학교실, ${ }^{2)}$ 환경보건센터 ${ }^{3)}$

\title{
Cognitive Behavioral Therapy in Childhood Tic Disorder : A Case of Report
}

\author{
Jung Rim Song, M.A. ${ }^{1)}$, Jong Woo Hong, M.D. ${ }^{2}$, Jin Ah Doh, M.A. ${ }^{1)}$, \\ Hyun Woo Kim, M.D. ${ }^{2)}$ and Myung Ho Lim, M.D. ${ }^{23)}$ \\ ${ }^{1)}$ Clinical Psychology Laboratory, Dankook Medical Center, Cheonan, Korea \\ ${ }^{2)}$ Department of Psychiatry, College of Medicine, Dankook University, Cheonan, Korea \\ ${ }^{3)}$ Environmental Health Center, Dankook Medical Center, Cheonan, Korea
}

\begin{abstract}
Chronic tic disorder or Tourette syndrome is known to be a chronic neuro-behavioral disease for which cognitive behavioral therapy (CBT) strategies have recently been introduced. Here, we report the effectiveness of CBT in a case of childhood chronic tic disorder, which is very common in clinical settings. The DSM-IV clinical diagnosis was applied by a child psychiatrist. The Yale Global Tic Severity Scale, Kovac's children's depression inventory, Spielberger State-Trait Anxiety Inventory, Abbreviated Conners' Rating Scales, and the Dupaul ADHD Rating Scales were used. This case involved a pharmacological treatment-refractory patient over the previous year. Thus, psychiatric consultation was undertaken. Subsequently, we administered five sessions of CBT for four weeks, consisting of symptom evaluation and planning, habit reversal training, and ventilation training. Following four weeks of CBT administration, there were improvements in the scores of the Yale Global Tic Severity Scale and the Clinical Global Improvement scale. Our observations indicate that CBT may be effective in the treatment of childhood tic disorder.
\end{abstract}

KEY WORDS : Tic Disorder · Tourette Syndrome · Cognitive Behavioral Therapy (CBT).

\section{서 론}

틱 장애 혹은 뚜렛 증후군은 갑작스럽고 불수의적인 운동 성 틱과 음성 틱에 의해서 특징적으로 관찰되는 소아기의 신 경질환이며, 1885년 프랑스 의사인 Georges Gilles de la Tourette에 의해서 처음 보고되었다.1) 외국 연구에서 틱 장애 의 유병률은 6 12\% 정도로 보고되고 있으며, ${ }^{2,3)}$ 우리나라의 경우는 아직 유병률에 대한 구체적인 역학연구 자료가 없다. 틱 장애는 발병연령이 5 7세경으로 대개 학습이 처음 이루 어지는 시기에 호발하며, 오랜 역사에도 불구하고 의외로 그 근본적인 원인에 대해서는 잘 알려지지 않은 신경질환이다.

접수완료:2010년 4월 21일 / 심사완료:2010년 6월 19일

Address for correspondence:Myung Ho Lim, M.D., Department of Psychiatry, College of Medicine, Dankook University, 359 Manghyang-ro, Cheonan 330-715, Korea Tel : +82.41-550-3945, Fax : +82.41-561-3007

E-mail : paperose@dku.edu
최근 틱 장애와 관계된 뇌의 병리적 기전은 감각운동 대뇌피 질-선조체-시상-피질 회로(cortico-striato-thalamocortical circuit, CSTC) 등의 신경회로 이상으로 제시되어 왔다. ${ }^{4,5)}$

일반적으로 틱 장애 치료 방법으로 약물치료가 주를 이루 고 있으나, 항정신약물 투여로 인한 진정, 인지적 둔감, 체중 증가, 우울, 불안 및 신경학적 행동 등의 부작용 위험성이 있 고, 비록 약물치료로 틱 증상이 감소하였을지라도 더 많은 증상의 감소를 위하여 인지행동치료(cognitive behavioral therapy, CBT)는 대안적인 혹은 보조치료로써 필요성이 있 을 것으로 생각된다.

틱 장애의 인지행동치료에는 이완훈련, 생체되먹임(biofeedback), 습관 뒤집기 훈련(habit reversal training, HRT) 등 이 치료 효과가 보고 된 바 있다. ${ }^{6)}$ 틱 증상은 전적으로 불수 의적인 증상으로 알려져 있었기 때문에 HRT처럼 수의적으 
로 틱을 조절하고자하는 인지행동치료는 최근까지도 틱 장 애의 임상치료에서 널리 수용되지 못하였다.

틱 장애의 인지행동치료적인 접근에서 가장 많이 연구된 방법은 HRT이며, 1973년 Azrin 등ㄱㅇㅔ 의해 처음으로 개발 되었다. Azrin과 $\mathrm{Nunn}^{7}$ 은 12 명의 틱 혹은 습관 행동 환아 를 대상으로 하여 1 회의 $\mathrm{HRT}$ 를 시행한 결과 $90 \%$ 의 증상 빈도 감소를 보였고, 3 개월 이후에도 $99 \%$ 의 증상 감소가 유 지되고 있음을 보고하였다. 이후에 틱 증상에 대해서 HRT 를 포함한 $\mathrm{CBT}$, 혹은 $\mathrm{HRT}$ 단독 치료의 효과에 대한 긍정 적인 결과가 지속적으로 보고되었다. ${ }^{8-11)}$ 또한, 최근 소아를 대상으로 한 연구에서 Piacentini 등른 25 명의 소아 청소 년 틱 장애를 대상으로 HRT와 자각훈련의 효과를 비교하였 는데, HRT에서 유의한 임상효과를 나타내었으며 3개월 이 후에도 그 효과가 유지되었다고 보고되는 등 최근 몇몇의 잘 고안된 임상연구에 의해서 그 임상적 효과가 지지되었다.

본 연구에서는 성인과 달리 임상적 사용 경험이 적었던 소 아 청소년 틱 장애를 대상으로 국내에서는 처음으로 HRT 및 호흡훈련을 주된 기법으로 하는 인지행동치료를 적용하 여 틱 증상이 개선된 1예를 경험하였기에 이를 보고하고 치 료 기법에 대해서 고찰하고자 한다.

\section{증 례}

환아는 만 10 세 여아로서 18 개월 전부터 나타난 불규칙한 안면 운동을 주소로 2008년 9월부터 $\bigcirc$ 대학교 의과대학 부속병원 정신과에 내원하였고 소아정신과 전문의의 임상적 인 면담을 통하여 정신장애의 진단 및 통계편람 4판(Diagnostic and Statistical Manual of Mental Disorders 4 edition, $\mathrm{DSM}-\mathrm{IV})^{13)}$ 진단 상 만성 운동성 틱 장애로 진단 되었다. 환아는 이후 6 개월 이상의 약물 치료에도 불구하고 틱 증상의 호전이 적었으며 동일한 진단 하에 규칙적으로 외 래에 내원하여 치료를 받고 있었다. 당시에 복용했던 약물은 투여 6개월 전부터 환자의 불안을 감소시키기 위한 목적으 로 escitalopram 10mg을 투여 중이었다. 2009년 7월 치료 자는 환아에게 인지행동치료를 병행하기로 계획하였고 대상 환아와 보호자에게 $\mathrm{CBT}$ 연구의 취지에 대해서 충분한 설명 및 상의를 하였으며 사전 동의를 받았고, 연구 방법에 대하 여 병원 윤리위원회의 심사 및 승인을 받았다.

환아는 3 녀 중의 장녀이며 영유아 발달력 상에서 특별한 문제는 발견되지 않았다. 가족력 상에서 어머니가 수년 전에 우울증으로 약물 치료를 받았던 적이 있었으며, 수개월간의 약물 치료 이후 우울증상이 호전되어 정상적인 일상생활을 유지하고 있었다. 환아는 비교적 활달하고 꼼꼼한 성격이며
학교성적은 상위권을 유지하고 있었다. $\mathrm{CBT}$ 계획 수립시기 당시에 환아에게 음성 틱은 발견되지 않았으며 첫 면담에서 팔 비틀기, 목 비틀기, 입술 씰룩거리기, 눈 깜빡이기 등의 근 육 틱만 발견되었다. 환아의 근육 틱은 불특정 주기로 호전 과 악화가 반복되는 양상이었다.

치료자는 2009년 7월부터 2009년 8월까지 일주일에 한 번씩 총 5 회, 4 주간의 $\mathrm{CBT}$ 를 환아와 보호자에게 시행하였 다. 환아에게 DSM-IV에 따른 임상적 진단을 시행하였으며, 역학 질문지와 임상척도 평가 등도 함께 시행하였는데, 틱 장 애에 많이 동반되어지는 $\mathrm{ADHD}$, 우울·불안장애를 함께 평 가하기 위하여 시행 전과 시행 후 1주, 4 주 후에 각각 Yale 틱 전반 척도(Yale Global Tic Severity Scale, YGTSS), ${ }^{14)}$ 임 상 인상 척도(Clinical Global Impression. CGI), ${ }^{15)}$ Conners' ADHD척도, ${ }^{16)}$ Dupaul ADHD척도, ${ }^{17,18)}$ Kovac's 우울 척도, ${ }^{19,20)}$ Spielberger 상태·특성 불안 척도 ${ }^{21)}$ 등을 평가하 였다. 각각의 회기는 90 분에서 2 시간정도가 소요되었으며 회기시간 외에 척도 및 임상 평가를 위한 시간을 추가로 배 정하였다.

본 환아에게 시행한 HRT의 방법은 Piacentini 등이 2009 년에 발행된 뚜렛 증후군 조절하기 치료자 지침서 ${ }^{22,23)}$ 와 2008 년 Behavior Sciences Consortium of the Tourette Syndrome Association(TSA)에서 추천한 Comprehensive Behavioral Intervention for Tics(CBIT)의 지침서 ${ }^{24}$ 를 중 심으로 시행하였다. 두 지침서 모두 임상적 경험 기반의 치료 지침서로서 HRT 및 이완훈련을 하는 것이 포함되어 있으며 아동 및 성인에게 모두 시행가능하다.

\section{1회기: 환아 증상 및 상태에 대한 관찰, 향후 계획 수립}

보호자와 환아에게 틱 장애에 대한 전반적인 교육을 실시 하였으며, 향후 4 주간 시행하게 될 틱 장애의 인지행동치료 에 대한 이론적 근거 및 치료과정을 소개하였다. 보호자와 환아에게 환아가 가지고 있는 틱 증상의 위계목록을 작성하 게 하였는데, 그 결과 환아는 입술을 씰룩거리는 행동, 목을 돌리는 행동, 팔을 비트는 틱 증상 등을 주로 호소하였다. 틱 증상의 위계목록 작성 이후 치료자는 환아에게 치료 동기를 강화하기 위한 방법으로 보호자와 함께 치료 참가에 대한 보상 계약서를 작성하게 하였다. 이러한 행동 보상 프로그램 은 틱 증상이 감소되었을 때보다는 환아가 치료에 열심히 참 여하였을 때 점수를 주는 방식으로 하였고, 특정 점수 이상 을 얻으면 이후 환아가 원하는 선물로 교환할 수 있도록 하 였다.

그 다음으로는 환아와 보호자에게 다음 치료까지 틱 일기 를 쓰도록 숙제를 할당하였다. 틱 일기는 HRT의 행동 기록 
및 유지 양식의 한 부분으로써 환아들이 치료기간 동안 자 신들의 틱 증상에 대해서 틱을 하였을 때 날짜, 시간, 장소 뿐 아니라, 누구와 있었는지, 그 당시 생각하거나 느낀 것에 대해 기록하도록 하였다. 이는 환아가 자신이 주로 틱을 하 는 상황을 자각하는 것을 배우고 회피 전략을 개발하는 데 에 도움을 줄 수 있다. 한 주 동안 환아의 틱 증상을 자세히 살피는 것의 중요성을 강조하기 위해 보호자와 환아를 분리 시킨 다음 틱 일기의 중요성에 대해 각각 다시 한 번 설명하 고, 틱 일기 작성법에 대해 교육하였다.

기능적 평가를 위하여 환경적 혹은 상황적인 요인이 틱 증 상에 어떻게 영향을 주는지에 대해서 알아보았다. 이러한 요 인에는 각각 내외적 선행요인 및 내외적 후속결과들이 있을 것으로 치료팀은 구분하였다. 외적 선행요인으로 환아는 다 른 사람들이 많은 학교보다는 오히려 집에 있을 때에 틱을 더 많이 나타내었으며 늦은 시간에 텔레비전을 볼 때에 틱 증상이 증가하는 것으로 평가되었다. 또한 내적 선행요인으 로 부모가 다툴 때처럼 환아가 불안을 느끼면 틱이 증가되 는 것으로 나타났으며 틱을 하기 직전에 증상 부위에 가려움 을 느끼는 등의 전조 감각 충동(premonitory urge)이 관찰 되었다. 외적 후속 결과로 환아는 틱 증상 이후 어머니의 관 심을 좀 더 받을 수가 있었으며, 내적 후속 결과로 전조 감각 충동 및 불안의 감소를 얻을 수 있었다. 치료자는 틱 장애 및 증상의 교육 뿐 아니라 이러한 환경적 혹은 상황적 요인 에 대해서 이번 회기에 환아 및 보호자와 토론하고 교육하 였다.

기능적 개입방법으로 환아의 불안이 틱을 악화시키고 있 다고 평가가 되었으므로 불안을 감소시키기 위한 호흡훈련 및 근육 이완훈련이 추천되었다. 또한 전조 감각 충동에 의 한 부적 강화요인이 평가되었으므로 이러한 요인을 차단하기 위하여 HRT를 계획하였다. 방과 후에 집에서는 부모님들이 부부싸움을 하는 모습을 환아에게 보여주지 않도록 주의하 였으며 가족 모두가 늦은 시간까지 텔레비전을 시청하는 것 을 금하였다. 한편, 이러한 상황에서의 틱 증상 악화에 대해 서는 부모님이 환아를 위로하지 않도록 교육하였다.

\section{2회기: 첫 번째 틱 증상인 입술 씰룩거리기에 대한 HRT}

$\mathrm{HRT}$ 는 자각훈련, 경쟁반응 훈련, 그리고 사회적 지지의 세 과정으로 구성되어 있다.

첫째로, 자각훈련은 틱 증상의 기술 뿐 아니라 틱 증상에 선행하는 전조 감각 충동을 알아차리고 전조 감각 충동과 틱 증상의 연관성을 이해하도록 하는 것이다. 치료자는 회 기 시간의 초반에 환아와 보호자에게 HRT에 대해서 다시 한 번 소개하였으며, 틱 장애의 HRT를 위해서는 틱 증상 전
에 환아가 느낄 수 있는 틱 신호에 대해 민감해져야 한다는 것을 강조하였다. 치료자는 환아에게 입술을 씰룩거리는 틱 증상에 대해서 자신이 좋아하는 이름을 붙이게 하였다. 환 아는 이 증상을 '짱구'라고 이름지었는데, 이러한 방법은 환 아에게 틱 증상에 대한 혐오감을 줄여주고 치료에 대한 친 근감을 높이게 하였다. 처음 틱 신호에 대한 느낌을 물었을 때에 환아는 어떤 느낌도 없다고 하였으나 방법을 조금 바꾸 어 환아에게 입술을 씰룩거리기 전에 검지 손가락을 먼저 들 게 하고 이후 입술을 씰룩거리게 하였다. 환아는 치료 시간 내내 이 행동 순서에 익숙해졌고 검지 손가락을 들고 입술을 씰룩거리기 시작하였다. 치료자는 환아에게 어떻게 입술을 씰룩거리기 전에 검지 손가락을 들 수 있었는지 설명하게 하 였고 환아는 틱 증상이 나타나기 전에 입술 주변의 가려운 느낌이 있었다고 말하면서 스스로 전조 감각 충동을 인식하 기 시작하였다.

둘째로, 경쟁반응훈련은 $\mathrm{HRT}$ 의 핵심과정이라고 할 수 있 다. 경쟁반응훈련은 틱에 대한 전조 감각 충동이 나타났을 때 혹은 틱이 시작된 직후에 환아가 적극적으로 시작해야하 는 대응 행동을 말한다. 치료자는 환아와 보호자에게 입술 을 씰룩거리는 틱 증상의 대응 행동으로 입술을 닫고 양쪽 어금니를 물게 하였고, 혀는 위쪽 앞니의 뒤편을 밀도록 하 였다. 이러한 경쟁반응훈련은 반드시 1 분 이상 틱이 사라질 때까지 수행하도록 하였으며 비교적 주위에서 자연스럽게 보 일 수 있도록 하였고 또한 환아가 다른 활동을 하면서도 이 훈련을 수행할 수 있도록 하였다. 초기에는 환아는 이러한 대응 행동을 힘들어 하였으나 충분한 연습 후에 비교적 자 연스럽게 대응 행동을 할 수 있었다. 치료자는 숙제로서 환 아와 보호자에게 다음 치료 회기까지 일정하게 시간을 정해 놓고 반복해서 연습을 하게 하였으며 틱 일기를 쓰는 것도 유지하게 하였다. 경쟁반응훈련은 30 분씩 하루 3 회 이상 수 행하도록 하였다.

셋째로, 사회적 지지는 환아가 경쟁반응을 하는 방법을 배 운 후에 가족 구성원들이 환아가 경쟁반응훈련을 하는 것을 도와주는 것을 말한다. 치료자는 가족 구성원 중에서 본 환 아를 도와줄 수 있는 지지자로서 어머니를 선정하였고, 지지 자인 어머니가 환아를 적극적으로 칭찬할 수 있도록 교육하 였으며, 어머니가 환아가 경쟁반응을 자주 상기할 수 있도록 언어적 자극을 줄 것을 함께 교육하였다. 또한 환아의 경쟁 반응훈련에 대해서 부모님이 칭찬과 함께 수행 점수를 기록 함으로써 긍정적 강화를 지속하도록 하였다.

\section{3회기: 두 번째 틱 증상인 목 비틀기에 대한 HRT}

지난주에 있었던 긍정적인 생활사건 혹은 부정적인 생활 
사건을 검토하였고 틱 증상의 위계 목록을 수정하였다. 숙제 와 보상프로그램을 확인하였으며 기능적 평가와 개입에 대 해서 재검토하였다. CBT 참여의 동기부여를 위하여 '어깨가 들썩여서 글을 쓰거나 운동을 할 때에 불편하다' 등 틱 증상 에 대해 불편한 점들을 기술하도록 하였다. 첫 번째 틱에 대 한 HRT를 확인하였으며 두 번째 틱에 대한 HRT 계획을 환 아 및 보호자와 상의하였다. 두 번째 틱인 목을 비트는 행동 을 환아는 '팽이'라고 이름 지었다. 환아는 이 근육 틱에 대한 틱 신호로 목이 아닌 어깨에서 오는 느낌 때문에 어깨를 들 썩이고 싶은 느낌이 들 때 자신도 모르게 목을 비트는 행동 이 나온다고 하였다. 환아가 이 틱 신호에 대해 민감해지게 하기 위해 치료자는 환아에게 어깨를 들썩이고 싶은 느낌이 들 때 검지 손가락을 올리도록 지시하였다. 환아는 2 주차에 시행했던 입술 씰룩거리기 틱보다 이번 틱 전조 감각 충동을 감지하는 것이 어렵다고 이야기하였다. 치료자는 환아에게 나타날 수 있는 의욕저하 및 좌절감에 대해서 충분히 격려 하였으며, 약 10 분간 환아와 보호자에게 틱 신호 감지 훈련 을 환아에게 적합하도록 독자적인 방법으로 시행한 후에 다 시 대응 행동에 대해 교육하였다. 환아에게 목 근육을 긴장 시킨 상태에게 어깨를 최대한 낮추게 하였다.

환아와 보호자에게 다음 인지행동치료 시간까지 세 가지 숙제를 하게 하였다. 환아와 보호자 모두 각각 틱 일기를 작 성하도록 하였고, 매일 시간을 정해서 틱 신호 훈련을 하도 록 하였다. 그리고 틱 신호 훈련을 한 다음에 대응 행동 훈 련을 약 30 분간 하루에 3 번 이상 수행하도록 하였다.

\section{4회기:세 번째 틱 증상인 팔 비틀기에 대한 HRT, 복식 호흡훈련}

틱의 위계목록에서 세 번째 틱은 팔을 비트는 근육 틱으 로 '오징어'라고 이름 지었다. 환아는 이 근육 틱에 대한 전조 감각 충동으로 팔에 뻐근한 느낌이 들어서 팔이나 손에 힘 을 줘야 된다고 했다. 이 근육 틱의 대응행동으로 치료자는 환아에게 양손을 엇갈리게 한 후 겨드랑이 밑에 넣도록 교육 하였다. 환아와 보호자의 틱 일기와 면담을 통해 환아는 부 모가 다툴 때에 틱이 증가하는 모습을 보였으며, 특히 환아 의 아버지가 골프채를 집어 들면 근육 틱이 심해진다고 보고 되었다. 환아 어머니는 환아 아버지와 상의해서 지난 한 주 동안에 환아가 보는 앞에서 부모가 다투거나 골프채를 집어 드는 모습을 보이지 않았다고 하였다.

환아와 어머니가 함께 복식호흡훈련을 하였다. 처음에는 치료자가 시범을 보이고 환아와 어머니가 함께 따라하도록 하였다. 어느 정도 익숙해졌을 때, 환아를 침대 위에 눕히고 어머니가 환아의 가슴과 배 위에 손을 얹게 하였다. 환아가
배 위에 풍선을 올려놓았다고 상상한 후 숨을 들이마시면서 배를 부풀이고 숨을 내쉴 때 배를 꺼지도록 하였으며 이러한 훈련을 치료 시간 동안에 매회 30 초 간 5 회 이상을 수행하 도록 하였으며 집에서도 반복하도록 교육하였다.

\section{5 회기: 이전의 틱 증상에 대한 HRT의 지속, 복식 호흡훈련과 치료 효과 평가}

지난주에 있었던 긍정적인 생활사건 혹은 부정적인 생활 사건을 검토하였고 기능적 평가와 개입에 대해서 재검토하였 다. 틱 증상의 경쟁 반응 훈련이 하루에 30 분 이상 이루어졌 는지 호흡 훈련이 하루에 5 분 이상 매일 수행되었는지 확인 하였으며 수행한 행동에 대해서 적절한 보상이 이루어졌는지 부모에게 확인하였다. 환아는 호흡훈련이 불안을 감소시키 는 데에 도움이 되었다고 보고하였다.

\section{치료 반 응}

환아는 매 치료 시마다 항상 어머니와 동반하여 병원을 방문하였고 주 1회(월요일) 그리고 4주째는 주 2 회(월요일과 금요일)씩 총 4 주간의 $\mathrm{CBT}$ 를 시행 받았다. $\mathrm{CBT}$ 시행 기간 및 이전 6 개월과 이후 3 개월 동안, $\mathrm{CBT}$ 시행 이전에 복용하 던 약물을 그대로 복용했으며 약물 용량의 변화는 없었다. 투여 약물은 escitalopram 10mg이었다.

YGTSS를 통해 틱 증상의 변화를 살펴보면 CBT 시행 전 YGTSS 근육 틱 점수 및 전반적 점수는 44점이었고, 시행 4 주 후에는 31점으로 감소하였으며 CBT 시행 전 YGTSS 장 애 정도 점수는 30 점이었고, 시행 4 주 후에는 20 점으로 감 소하였다.

또한 CGI 척도에서도 시행 전 점수는 4점이었고 시행 4주 후에는 3점으로 감소하였다. 그러나 Conners' ADHD척도 Dupaul ADHD척도에서는 각각 시행 전 점수가 10점/11점, 시행 4주 후에는 9점/8점으로 별다른 차이를 나타내지 않았 다. Kovac's 우울 척도에서는 시행 전 점수가 15점, 시행 4 주 후에는 10점으로 나타났다. Spielberger 상태/특성 불안 척도에서는 각각 시행 전 점수가 9점/9점, 시행 4주 후에는 8점/8점으로 나타났다(Table 1).

\section{토 론}

틱 증상에 대한 HRT의 치료 기전은 아직까지 잘 밝혀지지 않았다. 초기에 Azrin과 Nunn근 틱 증상의 발현과 대치되 는 근육의 긴장, 그리고 경쟁적 반응으로서 틱 증상을 과다 각성하는 기전을 언급한 바 있다. 그러나 경쟁반응이 목표가 
Table 1. Rating scales before and after 5 times of 4 weeks conitive behavior therapy with the child chronic motor tic disorder

\begin{tabular}{|c|c|c|c|c|}
\hline Rating scales & & & Baseline & 4 weeks \\
\hline \multirow[t]{12}{*}{ Yale tic scale } & Number & Motor tic & 2 & 1 \\
\hline & & Vocal tic & 0 & 0 \\
\hline & Frequency & Motor tic & 4 & 4 \\
\hline & & Vocal tic & 0 & 0 \\
\hline & Intensity & Motor tic & 3 & 1 \\
\hline & & Vocal tic & 0 & 0 \\
\hline & Complexity & Motor tic & 3 & 2 \\
\hline & & Vocal tic & 0 & 0 \\
\hline & Interference & Motor tic & 2 & 3 \\
\hline & & Vocal tic & 0 & 0 \\
\hline & Impairment & & 30 & 20 \\
\hline & Global & & 44 & 31 \\
\hline $\begin{array}{l}\text { Clinical global } \\
\text { impression }\end{array}$ & & & 4 & 3 \\
\hline \multirow[t]{3}{*}{ Dupaul ADHD } & Total & & 10 & 9 \\
\hline & & Inattention & 3 & 4 \\
\hline & & Hyperactivity & 7 & 5 \\
\hline Conners' ADHD & & & 11 & 8 \\
\hline $\begin{array}{l}\text { Kovac's } \\
\text { depression }\end{array}$ & & & 20 & 15 \\
\hline $\begin{array}{c}\text { Spielberger state } \\
\text { anxiety scale }\end{array}$ & & & 9 & 8 \\
\hline $\begin{array}{l}\text { Spielberger trait } \\
\text { anxiety scale }\end{array}$ & & & 9 & 8 \\
\hline
\end{tabular}

되는 틱 증상과는 다른 위치의 근육에서 시행하는 것이 더 욱 효과적이라는 연구결과 ${ }^{25}$ 가 나옴으로써 앞서의 가설은 이후에는 지지 받지 못하였다. Sharenow 등히은 경쟁반응 의 혐오적 특성이 틱 증상에 대해 벌로서 우연히 작용한다고 제안하였다. 이러한 설명은 경쟁반응이 자가 수행된 벌로 틱 증상과 우연히 짝 지워져 일종의 조작적 조건화로 작용함으 로써 치료효과를 가져온다고 보았다. 혹은 틱 증상에 대한 혐오자극으로서 경쟁반응을 의도적으로 적극 수행함으로써 환아의 치료 의지를 강화시키고 자기조절감을 증가시킬 수 있다고 보았다. 일부 연구자들은 HRT가 경쟁반응의 사용으 로 틱 증상을 억제하고 결과적으로 전조 감각 충동의 습관 화를 초래하는 것은 노출 및 반응방지(exposure and response prevention, ERP)와 유사한 기전이며 HRT와 ERP 의 임상효과에 있어서도 동등하다고 보고하였다. ${ }^{26)}$

역사적으로 틱 증상은 불수의적인 증상으로 알려져 왔지 만, Leckman 등은 틱 장애의 $90 \%$ 에서 틱을 조절해 보았 던 경험이 있었던 점에 주목하였고, 이후 몇몇 연구자들은 대부분의 틱 장애에서 나타나는 전조 감각 충동(premonitory urge)이 틱 증상의 발현 직전에 나타나는 것에 주목하 였다. ${ }^{27,28)} \mathrm{HRT}$ 의 핵심 기제라고 할 수 있는 전조 감각 충동
은 뚜렷한 국소 감각으로 나타나고 대부분에서 긴장감을 증 가시키며 이완된 신체부위를 움직임으로써 해소된다. 즉 전 조 감각 충동은 일종의 불쾌한 특성을 갖고 있기 때문에 틱 장애 환아는 이러한 전조 감각 충동을 해소하기 위해서 부 정적 강화기전에 의해 틱 증상을 발현시킨다는 것이다. ${ }^{29)}$ 한 편 전조 감각 충동(Premonitory urge)은 강박 장애에서 강 박사고와 강박행동의 관계처럼 전조 감각 충동과 틱 증상이 연관되어 나타나는 것으로 설명되기도 한다. ${ }^{30)}$ 즉, 강박 장애 에서 강박사고는 강박행동에 선행하여 나타나는 인지적인 특성의 증상으로 알려져 있는데, 전조 감각 충동 역시 행동 증상인 틱 증상에 선행해서 나타나는 인지적인 특성의 증상 이라는 것이다.

틱 증상의 HRT는 대개 10세 이상을 대상으로 하는데 그 러한 이유는 10 세 미만의 아동에서 전조 감각 충동 혹은 틱 증상을 자의적으로 조절하는 것이 비교적 힘들고 전조 감각 충동도 뚜렷하게 인식하지 못하기 때문으로 보인다. ${ }^{31,32)}$ 본 증례에서도 눈을 깜박이는 것과 같은 단순 틱 증상이 나타 났지만 오히려 이러한 단순 틱 증상은 복합 틱 증상에 비해 서 수의적으로 억제하기가 힘들기 때문에 틱 증상의 치료 위 계목록에서 제외하였다.

틱 장애는 특징적으로 증상의 기복을 가지고 있는 질환이 다. 본 증례에서 틱 장애는 최초 진단이후 1년 이상 외래에서 치료를 받았던 군으로 비교적 진단적인 안정성을 갖고 있었 지만 상대적으로 $\mathrm{HRT}$ 의 치료 기간 및 효과의 관찰기간이 짧았고, 이완 훈련에는 복식 호흡 훈련과 점진적 근육이완 훈련이 가장 널리 사용되고 있는데 본 증례에서는 아동이 근육훈련을 힘들어하여서 복식 호흡 훈련만을 적용하였다. 또한, 본 증례에서 HRT 후에 YGTSS척도에서 유의한 근육 틱 증상 및 음성 틱 증상의 개선이 나타났지만 한 명의 증례 에서 단기간의 임상적 증상 개선만으로 $\mathrm{CBT}$ 가 치료효과가 있다고 일반화하기에는 어려움이 있을 것이다.

본 증례에서는 $\mathrm{ADHD}$ 및 우울·불안장애가 동반되지 않았 지만 경한 정도의 불안증상을 환아가 지속적으로 호소하고 있어서 이러한 불안 증상을 감소시킬 목적으로 소량의 escitalopram을 투여하였다. 또한 본 증례에서 Conners' AD$\mathrm{HD}$ 척도 및 Dupaul ADHD 척도로 측정한 주의력결핍-과 잉행동 장애 증상에서는 유의한 차이를 나타내지 않았다. 이러한 결과에 대해서는 앞으로 좀 더 많은 환아를 대상으 로 하는 다수의 추후 연구를 통해서 확인이 필요할 것으로 보인다.

이러한 환아의 자료를 얻은 지역은 신흥 도시로서 노인인 구가 많은 농촌 지역의 특징을 반영한다고 보기는 어렵다. 또 한, 틱 장애는 남성이 많은 유병율을 나타내며 연령에 있어서 
도 학령기의 초기에 많이 발병되는 특성을 나타내는 질환이 다. 그러므로 향후 성과 연령 그리고 지역분포 등을 고려하고 좀 더 많은 환아를 대상으로 HRT 혹은 그 외에 다른 인지행 동치료기법을 시행하였을 경우와 정상 대조군 혹은 약물치 료 대조군 간의 차이를 비교할 수 있는 대규모 연구가 필요할 것이다.

\section{결 론}

틱 장애 혹은 뚜렛 증후군은 불수의적인 운동성 틱과 음 성 틱에 의해서 특징적으로 관찰되는 소아기의 대표적인 신 경질환이다. 본 연구자는 성인과 달리 임상적 사용 경험이 적 었던 소아 청소년 틱 장애를 대상으로 국내에서는 처음으로 $\mathrm{HRT}$ 및 호흡훈련을 주된 기법으로 하는 인지행동치료를 적 용하여 틱 증상이 개선된 1예를 경험하였기에 이를 보고하고 치료 기법에 대해서 고찰하였다.

중심 단어: 틱 장애 · 뚜렛 장애 · 인지행동치료.

\section{References}

1) Singer HS. Tourette's syndrome: from behaviour to biology. Lancet Neurol 2005;4:149-159.

2) Kurlan R, McDermott MP, Deeley C, Como PG, Brower C, Eapen $S$, et al. Prevalence of tics in school children and association with placement in special education. Neurology 2001;57:1383-1388.

3) Gadow K, Nolan E, Sprafkin J, Schwartz J. Tics and psychiatric comorbidity in children and adolescents. Dev Med Child Neurol 2002; 44:330-338.

4) George MS, Belmaker RH (eds). Transcranial Magnetic Stimulation in Clinical Psychiatry. Washington, DC: American Psychiatric Publishing, Inc.;2007.

5) Mink JW. Neurobioloy of basal ganglia and Tourette syndrome: basal ganglia circuits and thalamocortical outputs. Adv Neurol 2006; 99:89-98.

6) Piacentini J, Woods DW, Scahill L, Wilhelm S, Peterson AL, Chang S, et al. Behavior therapy for children with Tourette disorder: a randomized controlled trial. JAMA 2010;303:1929-1937.

7) Azrin NH, Nunn RG. Habit-reversal: a method of eliminating nervous habits and tics. Behav Res Ther 1973;11:619-628.

8) Peterson AL, Azrin NH. An evaluation of behavioral treatments for Tourette syndrome. Behav Res Ther 1992;30:167-174.

9) Azrin NH, Nunn RG, Frantz SE. Habit reversal vs negative practice treatment of nervous tics. Behavior Therapy 1980;11:169-178.

10) Peterson AL, Campise RL, Azrin NH. Behavioral and pharmacological treatments for tic and habit disorders: a review. J Dev Behav Pediatr 1994;15:430-441.

11) Wilhelm S, Deckersbach T, Coffey BJ, Bohne A, Peterson AL, Baer L. Habit reversal versus supportive psychotherapy for Tourette's disorder: a randomized controlled trial. Am J Psychiatry 2003;160: 1175-1177.

12) Piacentini J, Chang S. Habit reversal training for tic disorders in children and adolescents. Behav Modif 2005;29:803-822.

13) American Psychiatric Association. Diagnostic and Statistical Manual of Mental Disorders. 4th ed. Washington, DC: American Psychiatric Association;1994.

14) Leckman JF, Riddle MA, Hardin MT, Ort SI, Swartz KL, Stevenson J, et al. The Yale Global Tic Severity Scale: initial testing of a clinician-rated scale of tic severity. J Am Acad Child Adolesc Psychiatry 1989;28:566-573.

15) Guy W. ECDU Asessment Manual for Psychopharmacology, Revised. US Department of Health, Education, and Welfare, Bethesda, MD;1976.

16) Oh KJ. Parent training treatment effect study in Korean ADHD patients. Kor J Clin Psychol 1994;13:217-233.

17) DuPaul GJ. Parent and teacher ratings of ADHD symptoms: Psychometric properties in a community-based sample. J Clin Child Psychol 1991;20:245-253.

18) So YK, Noh JS, Kim YS, Ko SK, Ko YJ. The Reliability and Validity of Korean Parent and Teacher ADHD Rating Scale. J Korean Neuropsychiatr Assoc 2002;41:283-289.

19) Kovacs M. The children's depression inventory: A self-rated depression scale for school-aged youngsters. Unpublished manuscript. University of Pittsburgh;1983.

20) Cho SC, Lee YS. Development of the Korean form of the Kovacs' Children's Depression Inventory. J Korean Neuropsychiatr Assoc 1990; 29:943-956.

21) Spielberger CD, Gorsuch RL, Lushene RE. Manual for the state-trait anxiety inventory. Palo Alto: CA. Consulting Psychologist Press;1970.

22) Woods DW, Piacentini JC, Chang SW, Deckersbach T, Ginsburg GS, Peterson AL, et al. Managing Tourette Syndrome. -A behavioral intervention for children and adults; therapist guide- New York, NY: Oxford university press;2009.

23) Lim MH, Lee HJ, Doh JA, Park TW, Kim YS, Cho SC. Managing Tourette Syndrome. -A behavioral intervention for children and adults; therapist guide-. Seoul, Hakjisa;2010.

24) Behavior Sciences Consortium of the Tourette Syndrome Association. Comprehensive Behavioral Intervention for Tics (CBIT). 2009; http://www.tsa-usa.org/news/CBIT intro.html.

25) Sharenow EL, Fuqua RW, Miltenberger RG. The treatment of muscle tics with dissimilar competing response practice. J Appl Behav Anal 1989;22:35-42.

26) Bliss J. Sensory experiences of Gilles de la Tourette syndrome. Arch Gen Psychiatry 1980;37:1343-1347.

27) Leckman JF, Walker DE, Cohen DJ. Premonitory urges in Tourette's syndrome. Am J Psychiatry 1993;150:98-102.

28) Miguel EC, do Rosário-Campos MC, Prado HS, do Valle R, Rauch SL, Coffey BJ, et al. Sensory phenomena in obsessive-compulsive disorder and Tourette's disorder. J Clin Psychiatry 2000;61:150-156.

29) Scahill L, Chappell PB, Kim YS, Schultz RT, Katsovich L, Shepherd E, et al. A placebo-controlled study of guanfacine in the treatment of children with tic disorders and attention deficit hyperactivity disorder. Am J Psychiatry 2001;158:1067-1074.

30) Shapiro AK, Shapiro E. Evaluation of the reported association of obsessive-compulsive symptoms or disorder with Tourette's disorder. Compr Psychiatry 1992;33:152-165.

31) Chang S, Piacentini J. Childhood OCD and tic disorders. In Marsh D \& Fristad M (Eds.), Handbook of serious emotional disturbance in children and adolescents. New York: John Wiley;2000.

32) Leckman J, King R, Cohen D. Tics and tic disorders. In Leckman JF \& Cohen DJ (Eds.), Tourette's syndrome, tics, obsessions, compulsions: Developmental psychopathology and clinical care. New York: John Wiley;1999. 